\title{
Cognitive analysis of the socio-ecological and economic system of the region for choosing a sustainable development strategy (on the example of oil-producing regions of Russia)
}

\author{
Tatiana Ledashcheva ${ }^{1 *}$, and Vladimir Pinaev ${ }^{1,2}$ \\ ${ }^{1}$ Peoples' Friendship University of Russia (RUDN University), Faculty of Ecology, 6 Miklukho- \\ Maklaya St, Moscow, 117198, Russian Federation \\ ${ }^{2}$ Environmental Consulting Company FRECOM Ltd, Moscow, Russia
}

\begin{abstract}
To correspond with Strategy of Russian regional development and sustainable development aims, in the article we propose to base strategy development on the results of modelling and analysis of socioenvironmental-economic region systems in the form of oriented graphs. Authors developed model for oil exploring regions Urals Federal district, based on open source data and lacking information is identified, as well as types and ways of it's gathering for completion of the modelling process.
\end{abstract}

\section{Introduction}

In line with the law «On strategic planning in Russian Federation» administrations of all regions of Russia elaborated Development strategies, containing priority development tasks and each task has complex of measures aimed at solution. However, the law itself does not define sustainable socio-economic development or the criteria for its achievement, which makes it difficult to assess the appropriateness of the approved development strategy for a particular region. The criteria defined in the strategy and the planned values of individual parameters characterize mainly the development of the economy and, to a certain extent, the development of society in the region. However, it is not even certain whether the set of social criteria is sufficient, and the lack of sufficient and justified parameters characterizing the environmental aspects of regional development does not allow us to assert that the planned regional development is sustainable.

It is interesting, however, that social aspects are in some way connected with economic aspects. With the absence of a sufficiently developed economy, there are no means to implement social support. On the other hand, the presence of a developed economy does not guarantee social welfare.

So we believe that in order to develop a strategy for regional development, it is necessary, first of all, to have a system of criteria that characterize the region as a socioenvironmental and economic system as a whole. It is clear that for different regions such systems will be different, depending on the structure of the gross regional product, social

* Corresponding author: ledashcheva-tn@rudn.ru 
structure, geographical location and many others. In this article as an example we will consider the oil-producing regions.

As it is well-known, the concept of sustainable development appeared in 1987 in report «Our common future» by World Commission on Environment and Development [1]. Since that time scientific community, including Russian, spent a lot of time improving this concept and identifying criterions for it's assessment. Common trend of different "sustainable development" definitions is the unity of economic, environmental and social aspects. At the same time, as noted above, the criteria listed in the development strategies of the Russian regions, which mainly include indicators of economic and social development, can not be considered as criteria for sustainable development. Ignoring or not paying enough attention to environmental aspects in regional management can lead to environmental problems. This can endanger environmental security of Russia - component of national security.

The most complete system of sustainable criteria was developed in 1996 by the UN Commission on sustainable development. It includes 132 indicators (environmental, social, economic, institutional). In practice, the use of this system is not rational, primarily because of its cumbersome and difficult to collect information on all criteria. In 2001, at the conference on European statistics in Canada, a shortened system of 58 criteria was proposed. However, the application of this system for a particular region is not rational some criteria may not be applicable, some criteria may, on the contrary, be crucial for the region, and statistical information is not available for the evaluation of many criteria. Thus, each region should have its own system of criteria. Many scientific works are devoted to the development of criteria for different regions of Russia. for example [2,3], in which some approaches have a sufficiently deep methodological development [3].

However, we believe that even a fairly complete set of indicators that solves the problem of the description of condition or sustainable development of the region, cannot be a sufficient basis for the regional development strategy, because it does not take into account the relationship between the indicators. It should be borne in mind that each region is a unique system where each criterion is somehow related to the others, which means that measures aimed at improving one target criterion will affect all the others. Ignoring this fact can negatively affect the expediency of the development strategy of the region.

Therefore, it is not sufficient to collect a list of indicators to assess the state of the region in order to develop a regional development strategy. It is necessary to understand how important this or that factor is for the state of the region as a whole, based not on the views of the decision maker, but on the mechanism of functioning of the region as a whole. It is necessary to be able to predict, to what extent the change of this or that indicator will affect all other parameters as a whole. Actually, it is necessary to model development of the situation in the region at change of this or that parameter, i.e. to build a model of the region taking into account all parameters.

It should be noted that attempts to build a system of sustainable development indicators based on their mutual impact are also being made by different researchers, while statistical models of the impact of some indicators on others are being considered [4]. In our view, however, this approach lacks consistency, which implies that each indicator influences each one, directly or indirectly, and in some cases we can change the power of influence through some economic, social or legislative measures.

\section{Methodology}

In our work we are rely on methodology of socio-environmental-economic systems modelling in the form of oriented graphs (methodology of cognitive modelling), developed 
under supervision of V.I. Gorelov and described in detail [5]. Modelling process includes following stages:

1. Problem (goal) statement.

2. Identification of factors (subsystems) covering all aspects of the system operation within the framework of the task; factors are presented as vertices of the directed graph.

3. Each factor is associated with a numerical characteristic (indicator), the value of which can be measured

4. Figuring out the direct connections between the factors, they are represented by the arcs of the directed graph.

5. Investigation of strong connectivity of the directed graph and sufficiency of a set of factors.

6. Assignment to arcs of signs " + " or " - " depending on the nature of mutual influence obtaining a sign oriented graph.

7. Estimation of weight coefficients of arcs of the directed graph by direct calculation, statistics or expert evaluation. Obtaining a weighted directed graph and its vertex adjacency matrix.

8. Calculation of the pulse process and the system response to a single impact on each vertex. This includes an assessment of the stability of the simulated system, which is a necessary condition for the correctness of the model.

The reaction of the system is calculated by the formula (1)

$$
X=\lim _{k \rightarrow \infty} p\left(E+\sum_{i=1}^{k} A^{i}\right)
$$

Here $\mathrm{X}$ is a vector of values of indicators in fractions of initial values, $\mathrm{A}$ is a matrix of adjacencies of vertices of the directed graph, $p$ is a vector of initial pulse.

The reactions $\mathrm{X}(\mathrm{i})(\mathrm{i}=1, \ldots, \mathrm{n})$ of the system is calculated for the initial single effects on each factor separately.

9. Calculation of system weight coefficients characterizing the influence of each factor on the state of the system as a whole, using the formulas (2) developed by the authors of the method:

$$
W_{i}=\sum_{j=1}^{n} \frac{X(1)_{j}-\operatorname{sgn}(1)}{\max \left(X(1)_{j}\right)-\min \left(X(1)_{j}\right)}
$$

Here, $\operatorname{sgn}(\mathrm{i})$ is 1 if factor $\mathrm{i}$ is considered positive to assess the state of the region and -1 otherwise.

10. Analysis of the obtained weight coefficients, evaluation of the system. It can be concluded about the stable development of the system, stagnation or pre-crisis / crisis state of the system and the optimal directions of system management. Thus, the state of the system is a crisis, if for any factor i signs Wi and sgn(i) are different.

11. Proposals for the management of the system, the calculation of the response of the model to the proposed management activities, which may consist in both the impact on the factors and the change in the weights of connections between the factors.

Finally, if apply proposed methodology to the task of region modelling, we receive proved strategy for region development, based on current state of region.

\section{Results and Discussion}

The basic model of the region was developed to support decisions on oil production project management and presented in [6]. Based on it, and having studied the available strategic and statistical data available for the regions of KHMAO and YANAO [7], we have chosen to modelling the following factors: the number of population, quality of life (estimated as 
the average level of income, including the consumer price index); the level of satisfaction of citizens with the quality of life; recreational resources (the area suitable for recreation of citizens); forest resources; biodiversity; cattle breeding; traditional land use; oil production; real estate (number of dwellings built per year); morbidity; regional budget; infrastructure (length of paved roads); volume of pollutants emitted into the air per year; average level of air pollution (percentage of maximum permissible concentration (MPC); volume of wastewater discharge; Quality of water resources; soil contamination with oil products; municipal and industrial waste; unemployment rate; energy production. Fishing is also important for YANAO.

Analysis of open source data on selected regions allows to make following conclusions on quantitative content of the model.

There are data on oil and gas exploration, housing construction, morbidity, regional budget, average income, the length of paved roads. Environmental factors - emissions and discharges - are worse. Information on environmental investments does not provide data on how these investments will be used or information on the effectiveness of such investments. There is also no information about oil spills and oil pollution.

At the same time, reports on the socio-economic situation of the Yamal-Nenets Autonomous Okrug contain information on various budget items, the amount of social payments, profitability of enterprises, etc., which allows to directly calculate some of the weight coefficients of the economic sphere. There is insufficient data to assess social connections. For example, data on the average length of a sick leave are needed to directly assess the link "morbidity-standard of living". In order to assess the links with the "standard of living" factor, in addition to data on average income by industry, it is necessary to obtain information on the approximate number of employees in a particular industry. There is no information about the presence or absence of oil and gas industry allocations for the improvement and construction of roads.

For the statistical evaluation of certain economic relations (e.g., the impact of the budget on infrastructure), the financial data on the growth of consumer prices were recalculated.

As the result of open source data analysis we were able to calculate 14 weight coefficients of the bonds:

«unemployment-living standard» $=-0,03$;

«morbidity-living standard» $=-0,04348$;

«living standard - regional budget» $=0,286$;

«living standard - real estate» $=0,186$;

«regional budget - living standard» $=0,032282$;

«regional budget - real estate» $=0,824$;

«infrastructure - living standard» $=0,454375$;

«infrastructure - regional budget» $=0,003184$;

«real estate - living standard» $=0,409799$;

$\langle$ real estate - regional budget $\rangle=0,05$;

«cattle breeding - living standard» $=0,2906$;

«cattle breeding - regional budget» $=0,000549$;

«oil exploration - living standard» $=0,836033$;

«oil exploration - regional budget» $=0,115585$.

In addition, as a result of the calculation of statistical coefficients from open source data, we estimated 8 weight coefficients:

« living standard - morbidity» $=-0,017$; 
« living standard - cattle breeding» $=-0,5$;

«reginal budget - infrastructure» $=2,1$;

«infrastructure - unemployment» $=-0,3$;

«infrastructure- cattle breeding» $=-0,26$;

«cattle breeding - morbidity» $=-0,022$;

«oil exploration - unemployment» $=-0,1$;

«oil exploration - cattle breeding» $=-0,48$.

As already mentioned, some data on the above parameters were missing, we removed them from the model, replacing the connections associated with direct impact on disease, livestock, recreational resources. So, the cumulative impact of oil exploration on morbidity, which is increasing due to emissions, pollution of water bodies and various pollution from oil spills, is estimated at 0.0936 .

When using coefficients calculated by the statistical method, it should be borne in mind that they include both direct and indirect relationships. For example, we reduce the regional budget-infrastructure ratio for the model by the product of the regional budget-real estate and real estate - infrastructure ratios.

Processing of the expert survey results allowed to estimate the remaining arc weights. However, it should be noted that the composition of the expert group was not included neither the administration nor the people of the region. To correctly assess the coefficients, it is necessary to obtain information on the above aspects and conduct sociological research and surveys in the region. This work can be finished only with region administration support.

The calculation of the model give us next system weights:

$\mathrm{W}($ oil production $)=2$

$\mathrm{W}$ (cattle breeding $)=1,2$

$\mathrm{W}($ traditional land use $)=1,7$

$\mathrm{W}($ recreational resources $)=1,1$

$\mathrm{W}$ (unemployment rate $)=-0,7$

$\mathrm{W}($ morbidity $)=-1$

$\mathrm{W}($ regional budget $)=4$

$\mathrm{W}($ infrastructure $)=1,1$

$\mathrm{W}($ real estate $)=2,5$

$\mathrm{W}($ level of satisfaction with the quality $)=0,9$

$\mathrm{W}($ life quality $)=2$

$\mathrm{W}$ (number of population) $=2,5$

$\mathrm{W}($ energy production $)=1$.

The analysis of the results allow us to draw some preliminary conclusions, for example: the general state of the region can be characterized as stable development; the volume of oil exploration has a positive impact on the overall state of the region, but to a lesser extent than the volume of the regional budget. This is probably due to the fact that oil production is not a project of the region, but is carried out by state-level companies, that is, first of all, most of payments are sent to the state budget (not to the local budget), and secondly, most of the employees of these companies are not inhabitants of the region. Accordingly, it is necessary to maintain the exploration of hydrocarbons at a stable level (since the increase in exploration is currently impossible for objective reasons) and to develop various sources of income. The same analysis of region model with included suppositive projects of another 
activities can help to choose the best ones for the moment. Attention should be paid to the preservation of traditional land use, which is even more important than livestock farming. Morbidity in the region plays a more negative role than unemployment. Видимо это связано с недостаточной населенность региона (показатель численности населения оказывает положительное влияние даже в большей степени чем нефтедобыча).

In the course of the calculations, we saw that migration in the region is unsustainable, probably because of complex climatic conditions and simply because of the quality of life (its increase is as important for the region as oil production). But the increase in the population can be achieved in another way - a temporary increase due to tourism development. The obvious solution is to develop ecological tourism taking into account the maintenance of traditional land use. It should be noted that the introduction of the ecotourism mechanism will lead to a change in the structure of the region's connections, it can be assumed that as a result the number of recreational zones will increase.

However, it should be noted that these conclusions can not be absolutely reliable, because there is no reliable information about more than half of the model's weight coefficients and an expert method of their evaluation is used. At any rate, even if such scarce information is available, it is interesting to look at the dynamics of the coefficients, recalculating them in accordance with the new annual statistics, which is the subject of further research.

\section{Conclusions}

To summarize, we can make some conclusions.

We proposed a model of oil-producing regions of Russia as a socio-ecological and economic system, sufficient in terms of integrity.

The available official statistical information allows to directly calculate part of the coefficients related to the social and economic sphere without relying on the estimated regression coefficients.

However, the available information is categorically insufficient to estimate, even statistically, the coefficients of the environmental-social and environmental-economic parts of the model.

At the same time, the availability of the model makes it possible to quickly determine what kind of statistics or other information is necessary for its accumulation and use in strategic planning of sustainable development of a region and to develop forms for collecting this information.

Based on the available information, we have estimated weight coefficients of indicators of the region's condition, which could be taken into account in the strategic planning. Thus, the high weight of the budget indicator of the region with half the weight of the oil production indicator indicates the need to fill the budget from other sources, i.e. to develop other economic activities. Traditional land use, the weight of which is not much lower than the weight of oil production, may be underestimated in this regard. In addition, we should not forget about the possibility to influence the values of the connections coefficients of the model. Thus, in the current situation, investments in recreational zones (a simple increase in their number) will not pay off practically. But if we take into account the priority of traditional land use, the logical solution would be to develop ecotourism, which can change the model's relationships and bring both indicators to a higher value level for the region.

However, in order to be sure to draw similar conclusions and to integrate them into the sustainable development strategy, it is necessary to supplement the model with the currently missing information. 


\section{References}

1. Our common future. Report of WCED. URL: http://xn--80adbkckdfac8cd1ahpld0f.xn-p1ai/files/monographs/OurCommonFuture-introduction.pdf

2. Manyushis A.Y., Barsukov I.E., Regulation of sustainable development of a large region, city: problems, ways of reforming, innovations. (Mezhdunarodnyj Soyuz ekonomistov, Moscow, 2016) (in Russian).

3. Zhukov I.V., Bajbakov E.I., Ekologicheskij konsalting, 4, 2-10 (2008) (in Russian)

4. O.V. Bakanach, N.V. Proskurina and Y.A. Tokarev, SHS Web of Conferences, 62, 05001 (EDP Science, Les Ulis, 2019)

5. Gorelov V.I., Karelova O.L., Ledashchaeva T.N. System modeling in social and economic sphere, (Logos, Moscow, 2012) (in Russian)

6. T. Ledashcheva, V. Pinaev, International Multidisciplinary Scientific GeoConference Surveying Geology and Mining Ecology Management, SGEM, 18(1.5), 11-18 (STEF92, Sofia, 2018)

7. Official web-page Department of State statistic service for Tyumen oblast, KhantyMansyisky autonomous region - Yugra and Yamalo-Nenets autonomous district http://tumstat.gks.ru 